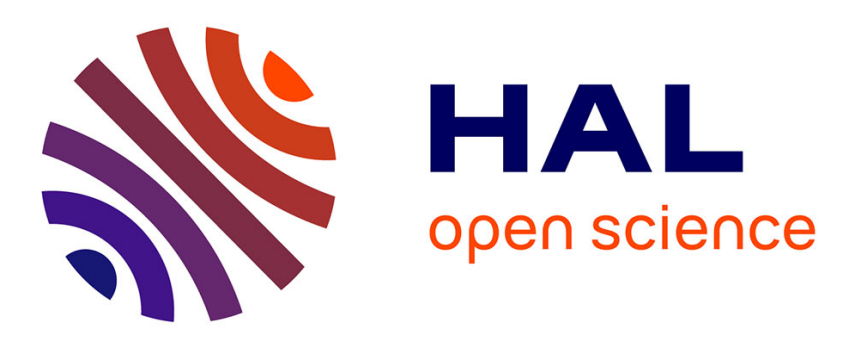

\title{
A New Metric of Image Quality Assessment for Stereoscopic Content
}

Jesus Jaime Moreno, Alessandro Rizzi, Christine Fernandez-Maloigne

\section{To cite this version:}

Jesus Jaime Moreno, Alessandro Rizzi, Christine Fernandez-Maloigne. A New Metric of Image Quality Assessment for Stereoscopic Content. AIC 2014, INTERIM MEETING international association of Colour, AIC, Oct 2014, Oaxaca, Mexico. pp.PP612-617. hal-01228275

\section{HAL Id: hal-01228275 https://hal.science/hal-01228275}

Submitted on 7 Dec 2015

HAL is a multi-disciplinary open access archive for the deposit and dissemination of scientific research documents, whether they are published or not. The documents may come from teaching and research institutions in France or abroad, or from public or private research centers.
L'archive ouverte pluridisciplinaire HAL, est destinée au dépôt et à la diffusion de documents scientifiques de niveau recherche, publiés ou non, émanant des établissements d'enseignement et de recherche français ou étrangers, des laboratoires publics ou privés. 


\title{
A NEW METRIC OF IMAGE QUALITY ASSESSMENT FOR STEREOSCOPIC CONTENT
}

\author{
Jaime Moreno*, Alessandro Rizzi†, and Christine Fernandez-Maloigneł \\ "Escuela Superior de Ingenierıa Mecánica y Eléctrica, Unidad Zacatenco. Instituto \\ Politécnico Nacional, 07738 Unidad Profesional Adolfo Lopez Mateos, Mexico. \\ † Dipartimento di Informatica, Università degli Studi di Milano, Via Comelico, 39/41 \\ 20135 Milano, Italy. \\ \#University of Poitiers, XLIM Laboratory, CNRS JUR 7252, 11 Bd Marie et pierre \\ Curie, 86962 Futuroscope cedex, France.
}

\begin{abstract}
Automatic or semi-automatic stereoscopic image quality assessment has arisen due to the recent diffusion of a new generation of stereoscopic technologies and content demand. Thereby, there is a growth in asking for algorithms of Stereoscopic Image Quality Metrics (SIQA). In this paper, we present a method for assessing the stereoscopic image quality, QUALITAS. QUALITAS is grounded on some human visual system features such as contrast sensitivity, effect of disparate image quality in left and right images, and distance perception, which do not depend on the images being tested. QUALITAS is defined in five stages. Instead of averaging individual qualities of the stereo-pair, QUALITAS introduces Contrast Band-Pass Filtering on a wavelet domain at both views, namely our algorithm perceptually weights left and right images depending on certain viewing conditions. This paper includes the comparison of 27 Metrics SIQA proposed by 16 authors, which summarizes the work made in this field in the recent five years, on image database LIVE 3D. Some algorithms can be combined with any 2D/Normal Image Quality Assessments (NIQA), giving as a result that QUALITAS was compared against 221 Metrics. QUALITAS obtained the best results in terms of overall performance of correlation coefficients. We conclude all metrics in SIQA-SET are simple modifications of NIQA, which take into account some extra characteristics from the disparity map (usually depth variances). Instead QUALITAS incorporates disparity masking in addition to divide 3D scenario in two parts: background and foreground planes. Moreover QUALITAS employs a contrast bandpass filtering, so dynamic parameters are considered as observational distance. It includes loss of correlation, luminance and contrast distortion. It takes into account the visual differences between left and right images, employing a penalization depending on their wavelet energy. Thus, the novelty of QUALITAS lies in combining some the best features of stereoscopic image quality assessments.
\end{abstract}

KEYWORDS: Stereoscopic image quality, Quality assessment databases, 2D image quality.

\section{INTRODUCTION}

Figure 1 depicts a general scheme of stereoscopic imaging, which is divided in three blocks objective assessment (in green), subjective assessment (in blue), and strength of relationship (in red). Objective assessment is a subsystem constituted by the following 
parts:

1) Input: Left and right images.

2) Process: Stereoscopic coding.

3) Output: Stereoscopic image.

4) Feedback: Stereoscopic image quality assessment (SIQA).

Bertalanffy in [1] proposed the general systems theory, which describes that Feedback verifies how efficient the Process is. So, the main goal of the SIQA is to measure in the stereoscopic image either image quality or degradation of the original stereo-pair whereas for the process of stereoscopic Coding is to obtain the least possible degradation of the original stereo-pair. In other words, any kind stereoscopic image coder employed in 3D Cinema, for instance, needs to support its results using a SIQA. This lead us to mention that the recent growth of stereoscopic algorithms goes hand in hand to the growth of the way to predict its quality. Thereby, the algorithms that assess the quality of a stereoscopic image has gained great importance.

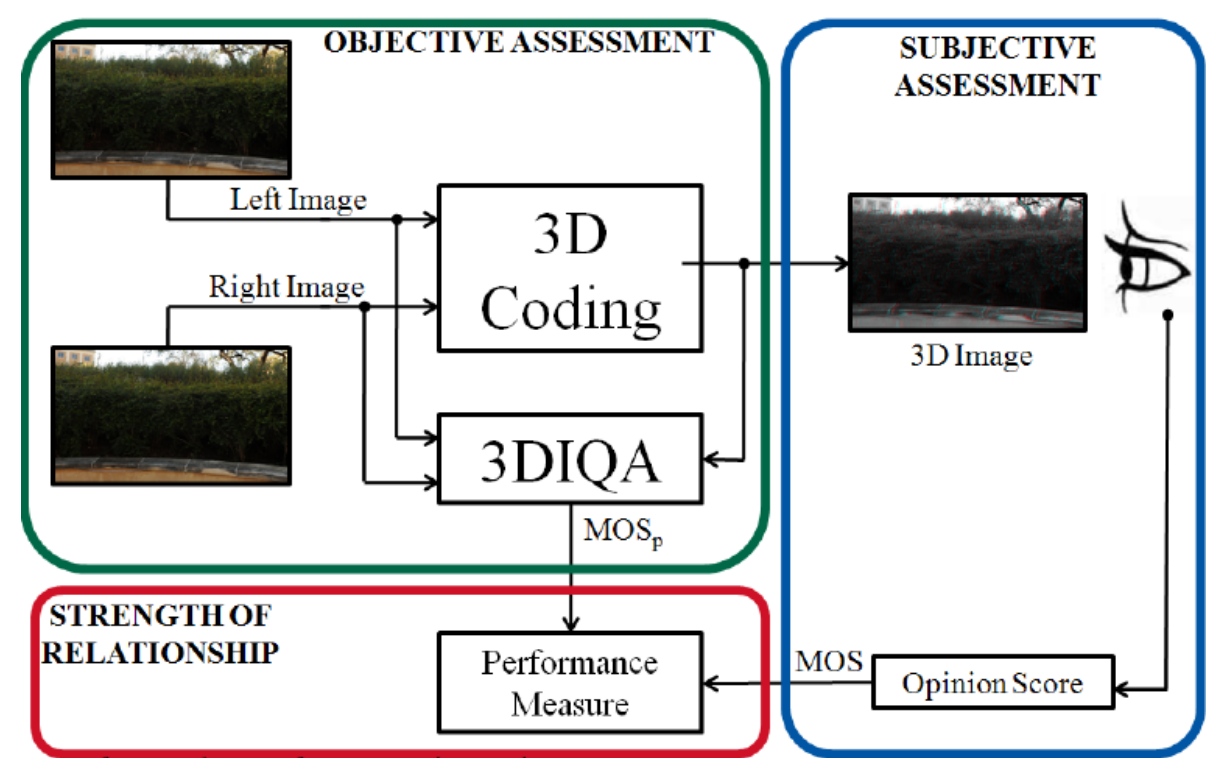

Figure 1. Block diagram of a general system for stereoscopic assessing.

It is reasonable to base SIQA from NIQA, since the observers employed in psychophysical experiments or subjective assessments [2], [3], [4] evaluate image quality from different slices in 2D scenario, which depend of the apparent distance.

\section{STEREOSCOPIC IMAGE QUALITY ASSESSMENTS}

\section{OBJECTIVE ASSESSMENTS}

From Figure 1 (green block, Objective Assessment), the main goal of any the stereoscopic image quality is to predict a subjective response, namely finding a predicted MOS (MOSp). Then, Table I shows the 27 stereoscopic metrics from 16 authors, this set of 27 metrics will be call henceforth SIQA-SET. It is worth noting that some authors propose more than one metric and we maintain the metric name 
that they gave them. Thus, we eventually will refer to a certain metric by the name that appears in the corresponding row, not by its author. Also, SIQA-SET was coded ourselves in MatLab.

Table 1. Stereoscopic image quality assessments.

\begin{tabular}{|c|c|}
\hline Algorithm & Metric \\
\hline Akhter et al. [4] & $A k M O S_{p}$ \\
\hline Benoit et al. [5] & $d_{1}$ \\
& $d_{2}$ \\
& $d_{3}$ \\
& $D d l_{1}$ \\
\hline Bosc et al. [6] & $Q_{s}$ \\
\hline Chen et al. [7] & $C_{m}$ \\
\hline Gorley et al. [8] & $S B L C$ \\
\hline Gu et al. [9] & $O D D M_{4}$ \\
\hline Hewage et al. [10] & $P S N R_{\text {edge }}$ \\
\hline Jin et al. [11] & $M S E_{m s}$ \\
& $M S E_{d p}$ \\
\hline Joveluro et al. [12] & $P Q M_{3 D}$ \\
\hline Mao et al. [13] & $Q_{\operatorname{mao}}$ \\
\hline Shao et al. [14] & $Q_{s h a o}$ \\
\hline Shen et al. [15] & $H D P S N R$ \\
\hline Solh et al. [16] & $3 V Q M$ \\
\hline Yang et al. [17] & $I Q A$ \\
& $S S A$ \\
\hline You et al. [18] & $Y o u D M O S_{p}$ \\
& $O Q Q$ \\
& $D Q_{\text {map }}$ \\
& $D Q_{\text {map }}$ \\
& $D Q_{\text {map }}$ \\
\hline Zhu et al. [19] & $e_{i}$ \\
\hline
\end{tabular}

\section{SUBJECTIVE ASSESSMENTS}

In the field of subjective stereoscopic image quality assessment, few image databases have been developed. We have employed LIVE 3D stereoscopic image database of the Laboratory for Image and Video Engineering of the University of Texas at Austin (USA. LIVE 3D contains standardized psychophysical experiments [40] and their stereoscopic images quality data are based on observer opinion score, collected with individual quality judgments, in Figure 1 the blue block Subjective Assessment). In each trial, the images are rated on a scale of excellent, good, fair, poor, and bad. Then, by means of statistical procedures, the data are processed, finally obtaining the mean opinion scores (MOS). Each stereoscopic image database applies different statistical procedures; the reader can refer to the citation for the details. Additionally, MOS merges results of different types in a form that allows the comparison with any kind of stereoscopic assessment metric. Since SIQA predicts subjective responses, namely it obtains a predicted MOS or MOSp.

\section{EXPERIMENTAL RESULTS}

From Figure 1 red block, strength of relationship between normalized MOS and MOSp is measured by a Performance Measure (PM), such as correlation coefficient. Strength of relationship gauges how strong is the tendency of two 
variables to move in the same or opposite direction. The performance measures used are:

- Spearman's Rank Ordered Correlation Coefficient (SROCC),

- Kendall's Rank Ordered Correlation Coefficient (KROCC),

- Pearson's Linear Correlation Coefficient (LCC) and

- Root-Mean-Squared Error (RMSE).

Any correlation coefficient value close to 1 indicates good correlation with human perception, while lower values of RMSE indicate better performance.

Table 2 shows the performance of an overall experimental result, which includes all SIQA of the SIQA-SET in addition to QUALITAS. Thus, QUALITAS correlates in $93.92 \%$ and $76.68 \%$, Figure 11 , being the metric that obtains the best LCC and KROCC, respectively. In terms of SROCC, the best ranking metric is d2 UQI, since it is best with $93.35 \%$. Also, based on these results, DQmap2 is the most accurate metric not only for all set of distortions considered but also for JPEG2000 and JPEG distortions. Regarding only these image compressiondistortions, QUALITAS is the best ranking metric in both distortions obtaining the highest correlation in both rank ordered coefficients.

Table 2. Overall performance across SIQA-SET including QUALITAS in predicting perceived stereoscopic image quality.

\begin{tabular}{|c|c|c|c|c|}
\hline Distortion & SIQA & NIQA & PM & Value \\
\hline \multirow{4}{*}{ ALL } & QUALITAS & none & LCC & 0.9392 \\
\hline & & UQI & SROCC & 0.9335 \\
\hline & QUALITAS & none & KROCC & 0.7668 \\
\hline & $D Q_{\text {map } 2}$ & none & RMSE & 0.1289 \\
\hline \multirow{4}{*}{ JP2K } & QUALITAS & none & LCC & 0.9467 \\
\hline & QUALITAS & none & SROCC & 0.9126 \\
\hline & QUALITAS & none & KROCC & 0.7443 \\
\hline & $D Q_{\text {map }_{2}}$ & none & RMSE & 0.0961 \\
\hline \multirow{4}{*}{ JPEG } & $d_{2}$ & UQI & LCC & 0.7620 \\
\hline & QUALITAS & none & SROCC & 0.7384 \\
\hline & QUALITAS & none & KROCC & 0.5396 \\
\hline & $D Q_{\text {map }_{2}}$ & none & RMSE & 0.0742 \\
\hline \multirow{4}{*}{ WN } & QUALITAS & none & LCC & 0.9333 \\
\hline & $d_{2}$ & MSSIM & SROCC & 0.9425 \\
\hline & $d_{2}$ & MSSIM & KROCC & 0.7911 \\
\hline & $d_{1}$ & BRISQUE & RMSE & 0.1001 \\
\hline \multirow{4}{*}{ Blur } & $d_{2}$ & UQI & LCC & 0.9558 \\
\hline & $M S E_{m s}$ & none & SROCC & 0.9318 \\
\hline & YouDMOS $_{p}$ & $\mathrm{AD}$ & KROCC & 0.7818 \\
\hline & $P S N R_{\text {edge }}$ & NAE & RMSE & 0.1156 \\
\hline \multirow{4}{*}{ FF } & QUALITAS & none & LCC & 0.8684 \\
\hline & QUALITAS & none & SROCC & 0.8256 \\
\hline & QUALITAS & none & KROCC & 0.6371 \\
\hline & $d_{2}$ & BPSNR & RMSE & 0.1116 \\
\hline
\end{tabular}

\section{CONCLUSIONS}

This paper includes the comparison of 27 Metrics SIQA proposed by 16 authors, which 
summarizes the work made in this field in the recent five years. Some algorithms can be combined with any NIQA, giving as a result that QUALITAS was compared against 221 Metrics.

QUALITAS obtained the best results in terms of overall performance of correlation coefficients either LCC, SROCC or KROCC with $93.92 \%, 93.34 \%$ (just $0.01 \%$ below the best one), and $76.68 \%$. For Root Mean Squared Error, QUALITAS did not get the best results, because it was developed with the aim of increasing any kind of correlation coefficient at certain times sacrificing accuracy.

We conclude all metrics in SIQA-SET are simple modifications of NIQA, which take in to account some extra characteristics from the disparity map (usually depth variances). Instead QUALITAS incorporates disparity masking in addition to divide 3D scenario in two parts: background and foreground planes.

\section{REFERENCES}

[1] L. V. Bertalanffy, Teoría General de los Sistemas, M. Fondo de Cultura Ecocómica, Ed., 1989.

[2] L. Goldmann, F. De Simone, and T. Ebrahimi, "Impact of Acquisition Distortion on the Quality of Stereoscopic Images," in Proceedings of the International Workshop on Video Processing and Quality Metrics for Consumer Electronics, 2010. [Online]. Available: http://mmspg.epfl.ch/

[3] X. Wang, M. Yu, Y. Yang, and G. Jiang, "Research on subjective stereoscopic image quality assessment," Multimedia Content Access: Algorithms and Systems III, pp. 725 509-725 509-10, 2009.

[4] R. Akhter, Z. M. Parvez Sazzad, Y. Horita, and J. Baltes, "No-referencestereoscopic image quality assessment," Stereoscopic Displays and Applications XXI, pp. 75 240T-75 240T-12, 2010.

[5] A. Benoit, P. Le Callet, P. Campisi, and R. Cousseau, "Quality assessment of stereoscopic images," EURASIP Journal on Image and Video Processing, vol. 2008, no. 1, p. $659024,2008$.

[6] E. Bosc, R. Pepion, P. Le Callet, M. Koppel, P. Ndjiki-Nya, M. Pressigout, and L. Morin, "Towards a new quality metric for 3-d synthesized view assessment," IEEE Journal of Selected Topics in Signal Processing, vol. 5, no. 7, pp. 1332-1343, 2011.

[7] M.-J. Chen, C.-C. Su, D.-K. Kwon, L. K. Cormack, and A. C. Bovik, "Full-reference quality assessment of stereoscopic images by modeling binocular rivalry," in Forty-Sixth Annual Asilomar Conference on Signals, Systems, and Computers, November 04-07, 2012.

[8] P. Gorley and N. Holliman, "Stereoscopic image quality metrics and compression," Stereoscopic Displays and Applications XIX, pp. 680 305-680 305-12, 2008.

[9] K. Gu, G. Zhai, X. Yang, and W. Zhang, "A new no-reference stereoscopic image quality assessment based on ocular dominance theory and degree of parallax," in 21st International Conference on Pattern Recognition (ICPR), 2012, pp. 206-209.

[10] C. Hewage and M. Martini, "Reduced-reference quality metric for 3d depth map transmission," in 3DTV-Conference: The True Vision - Capture, Transmission and Display of 3D Video (3DTV-CON), 2010, 2010, pp. 1-4. [11] L. Jin, A. Boev, A. Gotchev, and K. Egiazarian, "3d-dct based multiscale full-reference quality metric for stereoscopic video," in Proceedings of the Sixth International Workshop on Video Processing and Quality Metrics for Consumer Electronics (VPQM), 2012. 
[12] P. Joveluro, H. Malekmohamadi, W. A. C. Fernando, and A. Kondoz, "Perceptual video quality metric for $3 d$ video quality assessment," in 3DTV-Conference: The True Vision - Capture, Transmission and Display of 3D Video (3DTV-CON), 2010, pp. 1-4.

[13] X. Mao, M. Yu, X. Wang, G. Jiang, Z. Peng, and J. Zhou, "Stereoscopic image quality assessment model with three-component weighted structure similarity," in International Conference on Audio Language and Image Processing (ICALIP), 2010, pp. 1175-1179.

[14] F. Shao, W. Lin, S. Gu, G. Jiang, and T. Srikanthan, "Perceptual full-reference quality assessment of stereoscopic images by considering binocular visual characteristics," IEEE Transactions on Image Processing, vol. 22, no. 5, pp. 1940-1953, 2013.

[15] L. Shen, J. Yang, and Z. Zhang, "Stereo picture quality estimation based on a multiple channel hvs model," in 2nd International Congress on Image and Signal Processing (CISP), 2009, pp. 1-4.

[16] M. Solh, J. M. Bauza, and G. AlRegib, "3vqm: A 3d video quality measure," in IEEE Transactions on Image Processing, 2011.

[17] J. Yang, C. Hou, Y. Zhou, Z. Zhang, and J. Guo, "Objective quality assessment method of stereo images," in 3DTV Conference: The True Vision - Capture, Transmission and Display of 3D Video, 2009, pp. 1-4.

[18] J. You, L. Xing, A. Perkis, and X. Wang, "Perceptual quality assessment for stereoscopic images based on $2 \mathrm{~d}$ image quality metrics and disparity analysis," in Proceedings of the International Workshop on Video Processing and Quality Metrics, 2010. [19] Z. Zhu and Y. Wang, "Perceptual distortion metric for stereo video quality evaluation," WSEAS Trans. Sig. Proc., vol. 5, no. 7, pp. 241-250, Jul. 2009. 